Short Communication

\title{
GENDER DIFFERENCES IN CHILDHOOD POISONING
}

\author{
Pratik Vijay Tarvadi ${ }^{1}$, Shankar M. Bakkannavar', Vikram Palimar $^{3}$, \\ G. Pradeep Kumar ${ }^{4}$, Mahabalesh Shetty ${ }^{5}$ \& Sanjeev Badiger ${ }^{6}$
}

\begin{abstract}
${ }^{1}$ Assistant Professor, Department of Forensic Medicine, KSHEM A, NITTE University, M angalore
${ }^{2}$ Assistant Professor, ${ }^{3}$ Additional Professor, ${ }^{4}$ Professor \& HOD, Department of Forensic M edicine, Kasturba M edical College, Manipal, ${ }^{5} \mathrm{HOD}$, Department of Forensic M edicine, ${ }^{6}$ Associate Professor, Department of Community M edicine, KSHEM A, NITTE University, M angalore,

Correspondence:

Pratik Vijay Tarvadi

Assistant Professor, Department of Forensic Medicine, K.S. Hegde Medical Academy (kshema), NITTE University, Nitynanada Nagar, Deralakatte, Mangalore - 575 018, Karnataka, India Mobile : +9198453 06634, Phone : +91 8242203030, E-mail : pvtdr@yahoo.com
\end{abstract}

\begin{abstract}
:
Background : Accidental paediatric poisoning is a common medical emergency and also associated with a high morbidity and mortality in children. In developing countries like India, the poisoning emergencies are becoming a major cause of mortality in infants and toddlers. Among the various studies done on poisoning cases in our country, the study on poisoning is more or less only on adults and hence this study is taken up to understand the number of childhood poisoning cases (based on gender).
\end{abstract}

Method : A ten year record based cross sectional study from January 1999 to December 2008 was conducted at the Department of Forensic M edicine \& Toxicology, Kasturba M edical College, M anipal, to understand the magnitude of childhood poisoning cases among males and females at Kasturba Hospital, M anipal.

Results: M ale children were predominantly affected (male: female::1.32: 1). M ost of the poisoning cases occurred at home in both the genders with boy to girl ratio based on percentage in indoor poisoning being $0.92: 1$ and boy to girl ratio based on percentage in outcome being 1.06:1.

Conclusion : Our study examines the difference in place and outcome of poisoning among boys and girls to identify population at risk and give suggestions so as to reduce the morbidity and mortality.

Keywords: paediatric, poisoning, gender

\section{Background:}

Poisoning is an important health hazard and one of the leading causes of morbidity and mortality worldwide. Nearly one million people are affected globally every year (1). The mortality worldwide is estimated to be $0.6 \%$ of all deaths per year as per World Health Organization (WHO). In India deaths due to poisoning accounts for more than 50,000 people every year ${ }^{(2)}$. Poisoning affects all age groupsviz. pediatric, adult and geriatric.

\begin{tabular}{|c|}
\hline Access this article online \\
\hline Quick Response Code \\
\hline
\end{tabular}

Over 45,000 children and teenagers, worldwide, die from poisoning each year accounting approximately 123 children per day ${ }^{(3,4)}$. Poisoning constitutes $0.33 \%$ to $7.6 \%$ of total admissions in pediatric wards at various hospitals in India ${ }^{(5)}$. Most common agents involved in childhood poisoning are paraffin, kerosene, pesticides, including insecticides, rodenticides, herbicides, poisonous plants, animal or insect bites, over the counter medications, prescription drugs, household products such as bleach, disinfectants, detergents, cleaning agents, cosmetics and vinegar ${ }^{(3,4)}$.

Studies done worldwide on poisoning are more concentrated on the adult population and hence there is an inadequate data on the extremes of age groups namely pediatrics and geriatrics. The pediatric age group in true sense is the most vulnerable group due to persisting aggressiveness and immaturity in the children.

The present study attempts to gather pediatric poisoning cases in M anipal, and the associated gender differences to 
know the incidences in female category as female foeticide is still a problem of concern in our developing country. By our study we also want to formulate recommendations that could probably help to reduce the morbidity and mortality due to poisoning in children (general and specifically girl child).

\section{Method :}

Ethical approval was obtained from the Institutional ethical committee of Kasturba Medical College, Manipal, Karnataka, India.

The data for the present study is a retrospective research undertaken at the Kasturba Hospital, M anipal, which is a tertiary care teaching hospital, situated in coastal Karnataka, South India, for a period of 10 years (January 1999 to December 2008).

All the poisoning cases admitted to Kasturba Hospital, Manipal, in the pediatric age group (up to 18 years) ${ }^{(6)}$ during the study period were included.

The relevant data like age, sex, place of poisoning and outcome was obtained from the Clinical case records from M edical records department, Kasturba Hospital, M anipal.

The data obtained was tabulated and analyzed using SPSS (Statistical Package for Social Services) 11 software.

\section{Results:}

A total of 214 cases of poisoning in the pediatric age group were admitted at the Kasturba Hospital, Manipal, during the period of 10 years from January 1999 to December 2008, as depicted in the graph no. 1 .

In the present study, we observed that the boys (122) outnumbered the girls (92), with boy to girl ratio being 1.3:1, as depicted in the graph no. 2.

M ost of the poisoning cases occurred at home in both the genders, boys being $77 \%$ and girls $83.7 \%$; boy to girl ratio based on percentage in indoor poisoning being $0.92: 1$, as depicted in the table no. 1.

It was observed in our study that, $95.3 \%$ of cases reported to our hospital had survived while $4.7 \%$ cases had expired. It was clearly noted that the increased percentage of survived children was seen among boys (97.5\%) as compared to girls (92.4\%) and boy to girl ratio based on percentage in outcome being 1.06:1, as depicted in the table no. 2.

\section{Discussion :}

We noticed in our study that, there was a higher incidence of poisoning amongst boys in all the age groups corroborating with other studies $(5,7,8,9,1,1,11,12,13,1,1,15,16)$. This finding can be attributed to the more active and restless nature of boys as compared to girls. We also found that girl predominance in the age group of 16 to 18 years, showing a gender reversal. This gender reversal in the age group of 16 to 18 years can be attributed to the sensitive nature of the females in the region where they are ready to take such extreme steps after slightest humiliation in any forms viz. failure in the examinations, love failure, forceful marriage (against their will) etc. Second factor that could be responsible during this age group is due to the hormonal changes that take place in girls during their post puberty period. Studies done at Pakistan ${ }^{(15)}$ showed that poisoning victims were predominately girls at all age groups, indicating the varying trends at different places.

It was also observed in our study that a majority of incidences of pediatric poisoning cases (irrespective of gender bias) had occurred at home which clearly shows that parental care was not adequate and also the dangerous substances were in the reach of children. Similar findings were observed in previous studies conducted at national and international level ${ }^{(12,13,14,15)}$. Hence our study helps in sending across a message to all pediatricians that every parent has to be specifically explained about the continuous parental care that children should receive and also keeping dangerous substances out of reach of children.

Our study showed low mortality rate among study population, which could be owed to the early first aid given to them. In our study the survival rate was higher in boys as compared to girls, which again can be attributed to the fact 
that less care is given to girls when compared to boys as the present norms in society are still a male preferring. The mortality rate ranged from $0.1 \%$ to $16 \%$ in other worldwide studies ${ }^{(12,13,14)}$. No deaths were reported in a study conducted at Pakistan ${ }^{(15)}$ and another study done in Belgaum, India on 0-4 years age group ${ }^{(14)}$.

In the present study, the poisoning cases were divided based on gender differences to know the incidences in male and female categories. Though there were more number of poisoning cases seen among boys, more deaths have occurred among girls. This shows that both the genders are susceptible for poisoning; hence every child irrespective of gender requires the same amount of care.

Our study was limited to a single hospital study and hence this study needs a further research on a wide area to give a better area based findings.

\section{Conclusion :}

In our study we observed that boys were affected more often than the girls and poisoning occurred inside the house. M ortality rate was low because of appropriate first aid measures taken and immediate medical intervention.

Following measures can be suggested to decrease the morbidity and mortality of pediatric poisoning:

- Parental education and awareness

- Child resistant packaging

- Storage of poisonous substances out of reach of children.

- Proper disposal of poisonous substance and their containers after use

- Basichealth education during schooling

\section{Acknowledgements:}

I am extremely thankful to staff of Medical Records Department, Kasturba Hospital, M anipal for their kind help and assistance in collecting data.

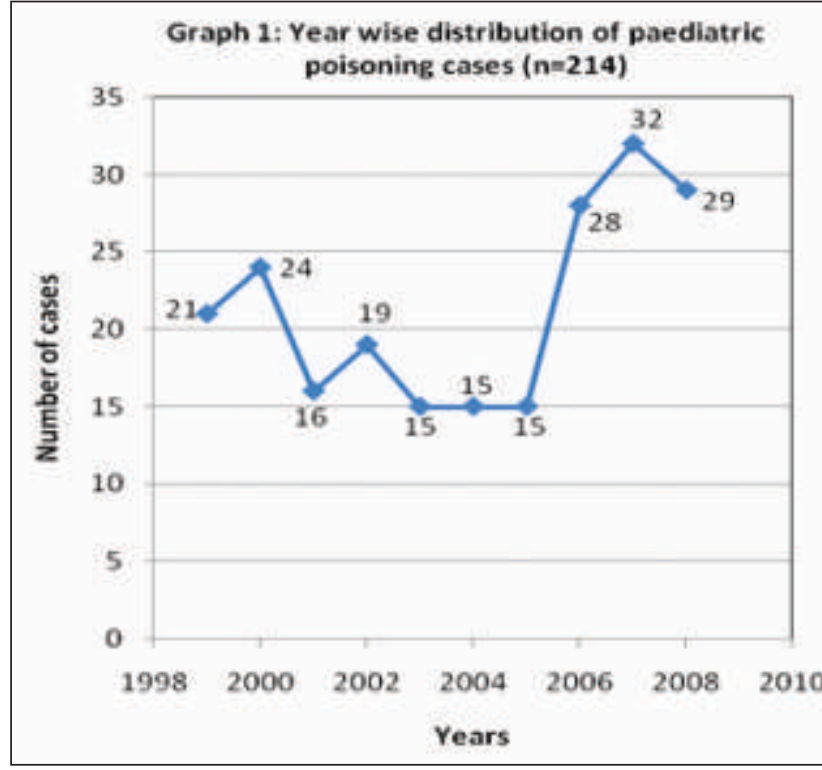

Graph 2 : Gender distribution in pediatric poisoning cases

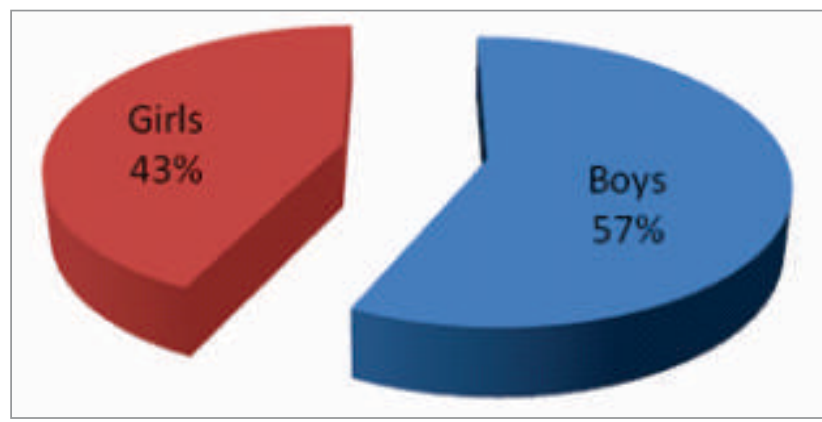

Table No. 1: Gender wise distribution of poisoning cases according to the place of Poisoning

$(n=214)$

\begin{tabular}{|l|l|l|l|}
\hline \multirow{2}{*}{ Gender } & \multicolumn{2}{|c|}{ Poisoning } & \multirow{2}{*}{ Total } \\
\cline { 2 - 3 } & At home & Outside home & \\
\hline Boys & $94(77.05 \%)$ & $28(22.95 \%)$ & $122(100 \%)$ \\
\hline Girls & $77(83.7 \%)$ & $15(16.3 \%)$ & $92(100 \%)$ \\
\hline Total & 171 & 43 & 214 \\
\hline
\end{tabular}

Table No. 2: Gender wise distribution of Outcome of poisoning cases

$(n=214)$

\begin{tabular}{|l|l|l|l|}
\hline \multirow{2}{*}{ Gender } & \multicolumn{2}{|c|}{ Outcome } & \multirow{2}{*}{ Total } \\
\cline { 2 - 3 } & Survived & Expired & \\
\hline Boys & $119(97.5 \%)$ & $3(2.5 \%)$ & $122(100 \%)$ \\
\hline Girls & $85(92.4 \%)$ & $7(7.6 \%)$ & $92(100 \%)$ \\
\hline Total & $204(95.3 \%)$ & $10(4.7 \%)$ & $214(100 \%)$ \\
\hline
\end{tabular}




\section{References:}

1. Arun M, Nagesh KR, Palimar V, Mohanty MK. Geriatric Poisoning Fatalities: A M anipal Perspective. Medico-legal Update. 2005; 5(1): 1 3.

2. Agarwal P, Handa R, Wali JP. Common Poisoning of India. Journal of Forensic M edicine and Toxicology. 1998; 15(1): 73-78.

3. http://www.who.int/violence_injury_prevention/ child accessed on 25th October 2010.

4. Dutta AK, Seth A, Goyal PK, Aggraval V, Mittal SK, Sharma R, et. al. Poisoning in Children: Indian Scenario. Indian Journal of Pediatrics. 1998; 65: 365-370.

5. Ahronheim JC, Howland MA. Geriatric Principles. In: Goldfrank's Toxicologic Emergencies. Edited by Goldfrank, Flomenbaum, Lewin, Howland, Hoffman, Nelson. 7th Edn. McGraw Hill Medical Publishing Division, USA: 2002; pp 1640-1646.

6. https://www.pediatriccareonline.org/pco/ub/view/Pediatric-DrugLookup/153856/0/ Definition_of_Age_Group_Terminology accessed on 16 th M ay 2011

7. The World Health Report. World Health Organization, Geneva: 2004

8. Injuries in the European Union Statistics summary 2003-2005. Eurosafe, Vienna: 2007.

9. Reith DM , Pitt WR, Hockey R. Childhood Poisoning in Queensland: An Analysis of Presentation and Admission Rates. Journal of Paediatrics and Child Health. 2001; 37: 446-450.
10. Mattila VM. Injuries and Their Risk Factors in Finnish Adolescents. School of Public Health. Tampere: University of Tampere. 2005.

11. Harel Y, Overpeck M D, Jones DH, Scheidt PC, Bijur PE, Trumble AC, et al. The Effects of Recall on Estimating Annual Nonfatal Injury Rates for Children and Adolescents. American Journal of Public Health. 1994; 84: 599- 605 .

12. Brayden RM, MacLean WE, Jr., Bonfiglio JF, Altemeier W. Behavioral Antecedents of Pediatric Poisonings. Clinical Pediatrics (Philadelphia).1993; 32: 30-35

13. Gauvin F, Bailey B, Bratton SL. Hospitalizations for Pediatric Intoxication in Washington State, 1987-1997. Archives of Pediatrics and Adolescent Medicine. 2001; 155: 1105-1110.

14. Vasvani V, Patil VD, Spectrum of Childhood Poisoning: A Belgaum Experience. Journal of Forensic M edicine and Toxicology. 1998; 15(1): 50-52.

15. Jan M A, Siddiqui TS, Haq IU, Khan Z. M ushroom Poisoning in Children: Clinical Presentation and Outcome; Journal of Ayub Medical College Abottabad. 2008; 20(2): 99-101

16. White SR. Pediatric Poisonings and Antidotes. In: Neonatal Pediatric Pharmacology - Therapeutic Principles in Practice. Edited by Yaffe SJ, Aranda 1.JV. 2nd Edn. Lippincotts Williams \& Wilkins, Philadelphia: 1992; pp 831-835. 